\title{
Using truck sensors for road pavement performance investigation
}

\author{
F. Perrotta, T. Parry, L. Neves \\ Nottingham Transportation Engineering Centre, Faculty of Engineering, University of Nottingham, \\ University Park, Nottingham NG7 2RD, UK
}

\begin{abstract}
Considering data from 260 articulated trucks, with 12900 cc Euro 6 engines driving along a motorway in England (M18), the study first shows how different approaches lead to the conclusion that road pavement surface conditions influence fuel consumption of the considered truck fleet. Then, a multiple linear regression for the prediction of fuel consumption was generated. The model shows that evenness and macrotexture can impact the truck fuel consumption by up to $3 \%$ and $5 \%$, respectively. It is a significant impact which confirms that, although the available funding for pavement maintenance is limited, the importance of limiting GHG emissions, together with the economic benefits of reducing fuel consumption are reasons to improve road condition (Zaabar \& Chatti, 2010).
\end{abstract}

\section{INTRODUCTION}

During the last decades, many studies claimed that well maintained roads may help in reducing costs due to the impact of pavement surface evenness and texture on vehicle fuel consumption (Sandberg, 1990, Laganier and Lucas, 1990, Beuving et al., 2004, Zaabar \& Chatti, 2010, among others). In particular, in a recent study, Zaabar \& Chatti (2010) claimed that pavement evenness can impact approximately $5 \%$ of the fuel consumption of road vehicles. Considering the case of England, a hypothetical reduction of just $2 \%$ in fuel consumption may be able to save up to $£ 1$ billion a year (Department for Transport, 2015). Thus, a complete life cycle assessment of road pavements including the impact of road conditions on vehicle fuel consumption in the use phase may lead to a review of the current road maintenance strategies with significant cost savings and reduction of greenhouse gas (GHG) emissions.

The main difference between this study and previous ones (e.g. Sandberg 1990, Zaabar \& Chatti 2010, Haider et al. 2011) is that in the past controlled experiments have been performed to collect data. Previous research tested only limited vehicles, repetitively driven at constant speed, in good weather (no rain, low wind speed, etc.) on selected segments of road, with no gradient, etc. Therefore, their conclusions may not be valid in general but only within their experimental conditions.

In this study data collected routinely from sensors installed as standard on trucks (SAE International,
2002) were analyzed. Modern trucks are fitted with many sensors that, via the combination of an Electronic Control Unit (ECU) and a Controller Area Network (CAN) bus, help fleet managers to control vehicle operating performance and costs. It may be feasible to use the same data to investigate the impact of pavement condition on truck fleet fuel economy.

Using a multiple linear regression, a predictive model for truck fleet fuel consumption including pavement surface condition measurements has been generated. This may be useful in future, to quantify possible cost savings and reductions in GHG emissions in pavement life cycle assessment (LCA) analyses including the use phase of road pavements.

\section{DATA}

Data from 260 trucks for one week of travelling along the M18 - a $42.6 \mathrm{~km}$ long motorway, part of the Strategic Road Network (SRN) of England and close to Doncaster - have been used for this study. Only trucks having $\sim 12900$ cc Euro 6 engines, and 6 axles in total ( 3 for the tractor and 3 for the trailer) have been considered due to the fact they represent the most common vehicle model in the investigated fleet.

Data records of various lengths and times (maximum 60 seconds or 1 mile $(1.61 \mathrm{~km})$ ), travelled at constant speeds $( \pm 2.5 \mathrm{~km} / \mathrm{h})$, between 79 and 94 $\mathrm{km} / \mathrm{h}$, in gear 12 , have been included in the analysis. 
The speed range includes the most common speeds for trucks on motorways. This resulted in 1420 records in total.

Data includes the vehicle profile (identifying a specific truck and its model), the gross vehicle weight (GVW, to the nearest $400 \mathrm{~kg}$ ), the travelled distance $(\mathrm{m})$, the travel date with time, and the fuel consumed (to the nearest 0.0011 ). This data is anonymized and is provided by Microlise Ltd, a company that uses them to analyze fleet performance for their clients, helping them to reduce operating costs.

Data concerning pavement condition comes from the national road agency (Highways England) and includes measurements of; road gradient (g, \%), radius of the road $(\mathrm{m})$, road crossfall (the transverse gradient of the road, \%), pavement evenness (LPV, longitudinal profile variance at 3,10 and 30 meters wavelength, in $\mathrm{mm}^{2}$ ), and macrotexture (SMTD, sensor measured texture depth, in $\mathrm{mm}$ ). All data are georeferenced. Table 1 summarizes the range of data included in the analysis:

\begin{tabular}{lrrrr}
\hline Data & Mean & Max & Min & St. Dev. \\
\hline $\begin{array}{l}\text { Fuel Consumption } \\
\text { (l/100km) }\end{array}$ & 29.71 & 60.00 & 0.13 & 13.86 \\
\hline $\begin{array}{l}\text { Gross Vehicle Weight } \\
\text { (kg) }\end{array}$ & 40300 & 58400 & 26000 & 7700 \\
\hline Road Gradient (\%) & 0.46 & 2.91 & -2.44 & 0.74 \\
\hline Vehicle Speed (km/h) & 89.14 & 93.94 & 79.20 & 1.99 \\
\hline LPV 10m (mm $\mathbf{2})$ & 0.87 & 3.60 & 0.20 & 0.35 \\
\hline SMTD (mm) & 1.20 & 1.86 & 0.46 & 0.21 \\
\hline
\end{tabular}

Table 1 - Summary of the data included in the analysis.

\section{METHOD}

A multiple linear regression analysis to predict the fuel consumption of vehicles among the considered truck fleet has been performed.

Only independent variables - including the gross vehicle weight (GVW), the road gradient, the road crossfall, the road radius, LPV at 10 metres wavelength and SMTD texture measurement - have been considered in the data analysis.

Although LPV at 3 and 30 metres wavelength data is available, this has not been included in the analysis due to its high correlation with the LPV at 10 metres wavelength and therefore they are not independent.

Because previous studies (e.g. Sandberg 1990) highlighted difficulties in assessing the impact of pavement surface conditions on vehicle fuel economy results, different statistics - adjusted $\mathrm{R}^{2}$, the Aikake Information Criterion (AIC), the forward variable selection statistic, and the Lasso regression have been used and the results compared. Similar results from different statistics give more confidence in the final conclusions.
Only variables selected by the forward variables selection and Lasso regression statistics are considered significant and thus included in the generated model. Among all the possible models, the ones showing higher adjusted $\mathrm{R}^{2}$ and lower AIC (Aikake (1973)) are considered.

\section{RESULTS}

The generated model has the following formula:

$$
\begin{aligned}
& F C=62.42+0.00024 G V W+14.84 g \%-0.57 s+ \\
& 0.26 L P V 10+0.87 \text { SMTD; }
\end{aligned}
$$

where:

$F C=$ fuel consumption, in $1 / 100 \mathrm{~km}$;

$G V W=$ gross vehicle weight, in $\mathrm{kg}$;

$g \%=$ road gradient, in $\%$;

$s=$ average vehicle speed, in $\mathrm{km} / \mathrm{h}$;

$L P V 10=$ evenness of the pavement surface, in $\mathrm{mm}^{2}$; and

$S M T D=$ pavement surface macrotexture, in $\mathrm{mm}$.

Results of the analysis of the adjusted $\mathrm{R}^{2}$, and the AIC, shows that the gross vehicle weight, the road gradient, and the vehicle speed are the variables that explain most of the variance of the fuel consumption for the considered truck fleet. Including LPV10 and SMTD measurements in the analysis, results in higher adjusted $\mathrm{R}^{2}$ and lower AIC coefficient. Road crossfall and radius were not significant variables for this study; including them in the analysis decreased the adjusted $\mathrm{R}^{2}$ and increased the AIC.

Tables 2 and 3 report the results of the adjusted $\mathrm{R}^{2}$ and the AIC. The asterisks highlight the variables included in the possible prediction models. Higher adjusted $\mathrm{R}^{2}$ shows higher significance of the variables included in the analysis.

\begin{tabular}{|c|c|c|c|c|c|c|c|}
\hline $\begin{array}{c}\text { adj- } \\
\mathbf{R}^{2}\end{array}$ & $\begin{array}{c}\mathbf{G V W} \\
\mathbf{( k g})\end{array}$ & $\begin{array}{c}\mathbf{g} \\
\mathbf{( \% )}\end{array}$ & $\begin{array}{c}\mathbf{s} \\
(\mathbf{k m} / \mathbf{h})\end{array}$ & $\begin{array}{c}\text { radius } \\
\mathbf{( m )}\end{array}$ & $\begin{array}{c}\text { cross- } \\
\mathbf{f a l l} \\
\mathbf{( \% )}\end{array}$ & $\begin{array}{c}\mathbf{L P V 1 0} \\
\left(\mathbf{m m}^{2}\right)\end{array}$ & $\begin{array}{c}\text { SMTD } \\
(\mathbf{m m})\end{array}$ \\
\hline 0.685 & $*$ & $*$ & $*$ & & & & $*$ \\
\hline 0.682 & $*$ & $*$ & $*$ & & & $*$ & $*$ \\
\hline 0.676 & $*$ & $*$ & $*$ & & & $*$ & \\
\hline 0.665 & $*$ & $*$ & $*$ & $*$ & & & \\
\hline 0.663 & $*$ & $*$ & $*$ & $*$ & $*$ & & \\
\hline 0.661 & $*$ & $*$ & $*$ & & & & \\
\hline 0.604 & $*$ & $*$ & & & & & \\
\hline
\end{tabular}

Table 2 - Summary of the analysis of the adjusted $R^{2}$ for the models.

For the AIC, lower values show higher significance of the included variables. 


\begin{tabular}{|c|c|c|c|c|c|c|c|}
\hline AIC & $\begin{array}{c}\text { GVW } \\
(\mathbf{k g})\end{array}$ & $\begin{array}{c}\mathbf{g} \\
(\mathbf{\%})\end{array}$ & $\begin{array}{c}\mathbf{s} \\
(\mathbf{k m} / \mathbf{h})\end{array}$ & $\begin{array}{c}\text { radius } \\
(\mathbf{m})\end{array}$ & $\begin{array}{c}\text { crossfall } \\
\mathbf{( \% )}\end{array}$ & $\begin{array}{c}\text { LPV10 } \\
\left(\mathbf{m m}^{2}\right)\end{array}$ & $\begin{array}{c}\text { SMTD } \\
(\mathbf{m m})\end{array}$ \\
\hline 2.93 & $*$ & $*$ & $*$ & & & & \\
\hline 4.51 & $*$ & $*$ & $*$ & & & & $*$ \\
\hline 5.23 & $*$ & $*$ & $*$ & & & $*$ & $*$ \\
\hline 12.32 & $*$ & $*$ & & & & & \\
\hline 23.55 & $*$ & $*$ & $*$ & $*$ & $*$ & & \\
\hline 25.03 & $*$ & $*$ & $*$ & $*$ & & & \\
\hline 28.87 & & $*$ & & & & & \\
\hline
\end{tabular}

Table 3 - Summary of the analysis of the AIC for the models.

Table 4 shows the results of the forward variable selection analysis. Asterisks highlight which variables are considered. The lower the number of asterisks and the higher is the significance of the considered variables.

\begin{tabular}{|c|c|c|c|c|c|c|}
\hline $\begin{array}{c}\text { GVW } \\
(\mathbf{k g})\end{array}$ & $\begin{array}{c}\mathbf{g} \\
(\mathbf{\%})\end{array}$ & $\begin{array}{c}\mathbf{s} \\
(\mathbf{k m} / \mathbf{h})\end{array}$ & $\begin{array}{c}\text { radius } \\
(\mathbf{m})\end{array}$ & $\begin{array}{c}\text { crossfall } \\
(\mathbf{\%})\end{array}$ & $\begin{array}{c}\text { LPV10 } \\
\left(\mathbf{m m}^{\mathbf{2}}\right)\end{array}$ & $\begin{array}{c}\text { SMTD } \\
(\mathbf{m m})\end{array}$ \\
\hline & $*$ & & & & & \\
\hline$*$ & $*$ & & & & & \\
\hline$*$ & $*$ & & & & & $*$ \\
\hline$*$ & $*$ & $*$ & & & & $*$ \\
\hline$*$ & $*$ & $*$ & & & $*$ & $*$ \\
\hline$*$ & $*$ & $*$ & & $*$ & $*$ & $*$ \\
\hline
\end{tabular}

Table 4 - Summary of the forward variable selection analysis.

In particular it is possible to see that the forward variable selection highlights the road radius and the road crossfall as the less significant variables for predicting the vehicle fuel consumption. This statistic also shows higher significance of the SMTD (the texture) compared to the vehicle speed. However, this might be due to the fact that this study only considers a narrow range of speeds.

Finally, looking at the results of the Lasso regression* (Equation 2) it is possible to see that the coefficients assigned to LPV10 and SMTD are low but they are not reduced to zero by the algorithm due to their significance.

$F C=0.14 G V W+0.87 g \%-0.27 s+0.02 L P V 10$

+0.02 SMTD;

where:

$F C=$ fuel consumption, in $1 / 100 \mathrm{~km}$;

$G V W=$ gross vehicle weight, in $\mathrm{kg}$;

$g \%=$ road gradient, in $\%$;

$s=$ average vehicle speed, in $\mathrm{km} / \mathrm{h}$;

$L P V 10=$ evenness of the pavement surface, in $\mathrm{mm}^{2}$; and

$S M T D=$ pavement surface macrotexture, in $\mathrm{mm}$.

* In the Lasso regression data are normalized to zscores (minus the mean and divided by the standard deviation) and this is why the parameters of Equation 2 are different from Equation 1.

\section{DISCUSSION}

From the analysis of the adjusted $\mathrm{R}^{2}$, the AIC coefficient, the forward variable selection, and the Lasso regression it is not possible to exclude that pavement surface conditions impact truck fleet fuel consumption. Table 2 shows that high adjusted $\mathrm{R}^{2}$ is obtained including gross vehicle weight, road gradient, vehicle speed, pavement evenness and texture in the model.

From the analysis of the AIC (Table 3 ) it is possible to see that gross vehicle weight, road gradient, and vehicle speed are the most significant variables. However, it can also be seen that LPV10 and SMTD are highlighted as the next most important variables. Including these variables in the model does not increase the AIC coefficient significantly. Therefore, the generated model includes LPV10 and SMTD measurements.

Table 4 shows that the forward variable selection considers the SMTD more important than the vehicle speed and classifies the LPV10 as the $5^{\text {th }}$ most important variable to include in the generated model. Also in this case it is highlighted that road radius and road crossfall can be excluded from the predicted vehicle fuel consumption of the truck fleet considered.

Finally, performing the Lasso regression we have one more confirmation of our hypothesis. In fact, the parameter of LPV10 and SMTD are not reduced to zero by the algorithm. This means that it is not possible to exclude the LPV10 and SMTD when predicting the fuel consumption of the considered truck fleet. It is also important to observe that road radius and road crossfall are excluded from the model generated by the Lasso regression statistic due to their low significance.

In the initial phase of this research (Perrotta et al. 2017) a similar model was generated for a different population of similar trucks, using engine torque as a surrogate for GVW, lower resolution fuel measurements and considering only one speed $(85 \mathrm{~km} / \mathrm{h})$. The correlation coefficient between predicted and measured fuel consumption for the model in this paper is 0.82 . This value is significantly higher than that in the initial phase (0.66) and this highlights the importance of the GVW measurement on the truck fuel consumption, confirming what previous studies have found (Sandberg 1990, Beuving et al. 2004, and Zaabar \& Chatti 2010).

The generated model shows that the impact of pavement evenness on fuel consumption for these data records can be up to $3 \%$, and up to $5 \%$ for macrotexture, calculated by comparing the estimated fuel consumption using the average values for gross 
vehicle weight, gradient and speed, compared to that by including in the estimate the maximum value for the texture or evenness. This compares to an esti- mate of 'approximately 5\%' for the impact of evenness reported by Zaabar \& Chatti (2010) for a study in the US.

\section{Linear regression: predicted fuel consumption vs real measurements}

referred to 1420 travels on the M18, for trucks with $3+3$ axles articulated and engine $\sim 12900 \mathrm{cc}$ euro 6

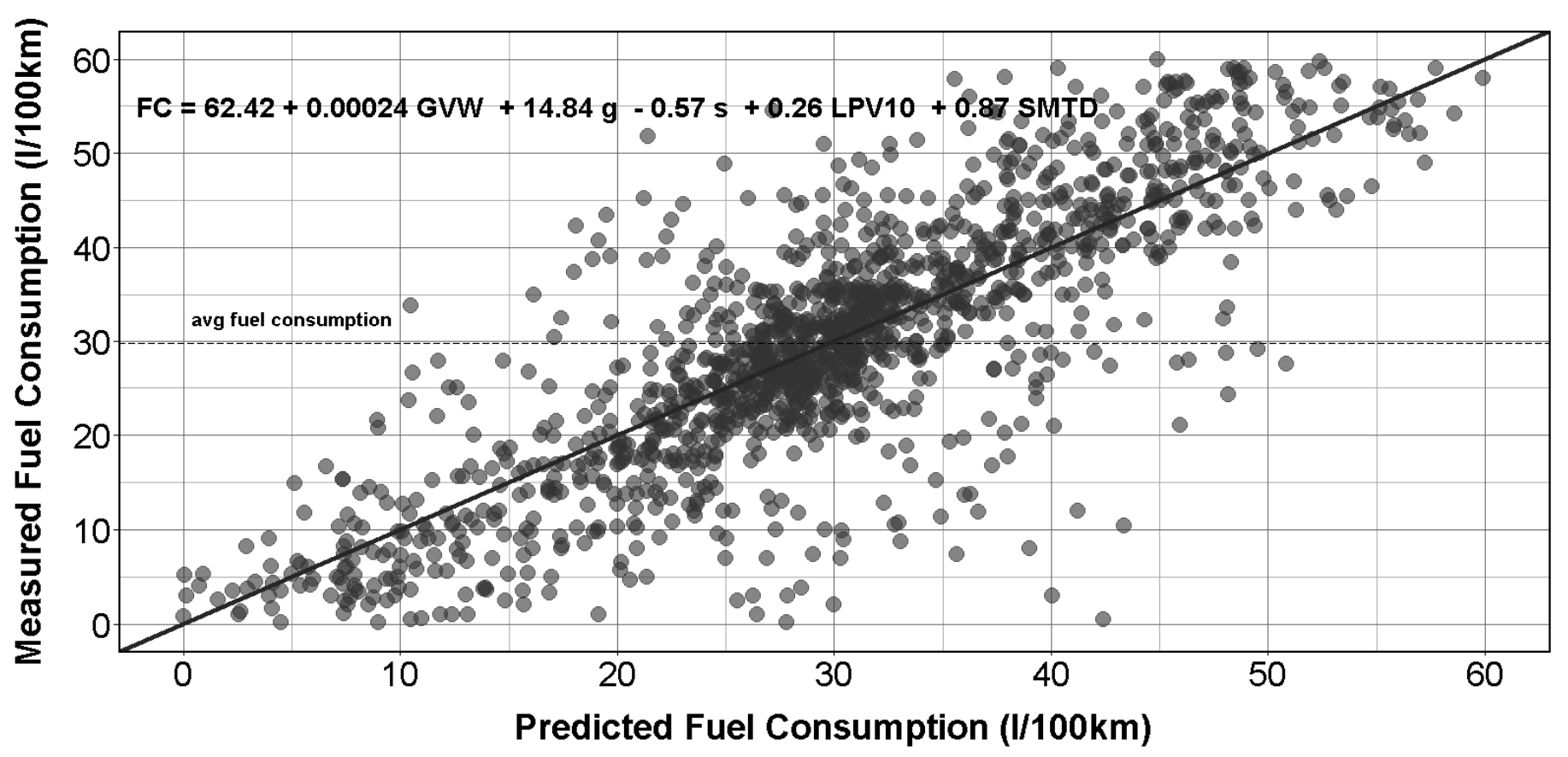

Figure 1- Comparison between predicted and measured fuel consumption.

This paper considers only one truck configuration and only a restricted range of speeds, but it introduces a general methodology that can be widely applied to different truck types and conditions.

The generated model tends to overestimate low fuel consumption and underestimate high fuel consumption (Figure 1). This behavior was also shown by Zaabar \& Chatti (2010).

\section{CONCLUSIONS}

The generated model shows that the variables with most impact on fuel consumption are the gross vehicle weight, the road gradient, and the vehicle speed. This was expected from the results of previous studies (Sandberg 1990, Beuving et al. 2004, Zaabar \& Chatti 2010).

This study confirms that pavement surface conditions can significantly impact truck fleet fuel consumption. The fact that different statistical approaches arrive at similar conclusions gives us confidence that pavement surface conditions influence vehicle fuel economy. This confirms the findings of previous studies using different approaches (Sandberg 1990, Beuving et al. 2004, Zaabar \& Chatti 2010) and gives us confidence in this 'Big Data' approach. The truck fleet performance and road condition data used in this study have been col- lected for other purposes and are widely available for similar studies if road agencies and truck fleet operators choose to co-operate.

Although the study shows that the impact of pavement surface condition on truck fleet fuel consumption is significant for this data set, further work is still needed. Validation of these conclusions, including more vehicle models, the influence of weather conditions (e.g. wind speed and direction), a wider range of vehicle speeds, and road conditions, will increase the applicability of the results. More sophisticated predictive statistics may also help in reducing bias and increase the reliability and precision of the final estimates.

\section{AKNOWLEDGMENTS}

The authors would like to thank all the partners involved in the project. These are Alex Tam of Highways England for giving us permission to use data from HAPMS, Mohammad Mesgarpour and Ian Dickinson from Microlise Ltd for allowing us to use an anonymized part of their truck telematics database and for their help in the data analysis and interpretation of results. Emma Benbow, David Peeling and Helen Viner from TRL Ltd for their support in this initial part of the research. 


\section{REFERENCES}

Akaike H, 1973. Information theory and an extension of the maximum likelihood principle. In Second International Symposium on Information Theory, ed. B. N. Petrov and F. Csaki, 267-281. Budapest: Akailseoniai-Kiudo.

Beuving E, De Jonghe T, Goos D, Lindhal T, and Stawiarski A, 2004. Environmental Impacts and Fuel Efficiency of Road Pavements. Industry Report. Eurobitume \& EAPA Brussels.

Chatti K and Zaabar I, 2012. Estimating the Effects of Pavement Condition on Vehicle Operating Costs, National Cooperative Highway Research Program, Report nr 720.

Washington, DC.

Department for Transport 2015. Transport energy and environment statistics. Government of the United Kingdom, UK.

Haider M, Conter M, and Glaeser KP 2011. Discussion paper what are rolling resistance and other influencing parameters on energy consumption in road transport, Models for Rolling Resistance in Road Infrastructure Asset Management Systems (MIRIAM), AIT, Austria.

Laganier R and Lucas J 1990. The Influence of Pavement Evenness and Macrotexture on Fuel Consumption. ASTM STP 1031 pp. 454-459.

SAE International 2002. Vehicle Application Layer - J1939-71 - Surface Vehicle Recommended Practice Rev. Aug. 2002.

Sandberg, USI. 1990. Road Macro- and Megatexture Influence on Fuel Consumption. ASTM STP 1031 pp. 460-479.

Perrotta F, Trupia L, Parry T, and Neves L 2017. Route level analysis of road pavement surface condition and truck fleet fuel consumption. Pavement LCA Symposium 2017, Urbana-Champaign, Illinois (USA).

Zaabar I and Chatti K, 2010. Calibration of HDM-4 models for estimating the effect of pavement roughness on fuel consumption for U. S. conditions. Transportation Research Record, (2155), pp.105-116. 